\title{
Post-transplant CD4+ non-cytotoxic $\gamma \delta$ T cell lymphoma with lymph node involvement
}

\author{
Kristin H. Karner ${ }^{1}$ (D) $\cdot$ Madhu P. Menon ${ }^{2} \cdot$ Kedar V. Inamdar $^{2} \cdot$ John L. Carey ${ }^{2}$
}

Received: 18 July 2018 / Accepted: 22 August 2018 / Published online: 8 September 2018

(C) Springer-Verlag GmbH Germany, part of Springer Nature 2018

\begin{abstract}
Gamma delta T cells represent a minor subset of the normal lymphocyte component of the human immune system, largely inhabiting mucosal surfaces. Gamma delta T cell lymphomas ( $\gamma \delta \mathrm{TCLs}$ ) are thought to be derived from these cells and are rare, extremely aggressive lymphomas that typically exhibit a cytotoxic phenotype and often present in extranodal sites, most commonly as cutaneous or hepatosplenic subtypes. The immunophenotype usually lacks both CD4 and CD8 expression, but occasional cases express CD8. CD4 expression in $\gamma \delta$ TCLs is exceedingly rare. The few reported cases tend to show a noncytotoxic phenotype with preferential involvement of the lymph nodes. Cases showing cutaneous presentation or with an immunosuppressive clinical history, while relatively common among typical $\gamma \delta$ TCLs, are even rarer among this unusual CD4+ subset. While this very small group appears to have an equally dismal prognosis to other types of $\gamma \delta$ TCL, little else is known as to how they may differ biologically and whether they should be treated as a separate entity. We report a unique case of CD4-positive gamma delta $\mathrm{T}$ cell lymphoma with skin and systemic lymph node involvement in the post-transplant setting.
\end{abstract}

Keywords $\gamma \delta \mathrm{T}$ cell lymphoma $\cdot$ Nodal-based $\gamma \delta \mathrm{T}$ cell lymphoma $\cdot \mathrm{CD} 4 \cdot$ Primary cutaneous $\gamma \delta \mathrm{T}$ cell lymphoma

\section{Introduction}

In the normal immune response, $\mathrm{T}$ cells recognize foreign antigens through the $\mathrm{T}$ cell receptor. Most of these $\mathrm{T}$ cell receptors are composed of the alpha beta heterodimer, but a minor subset of T cells (less than 10\%) in the peripheral blood expresses the gamma delta $(\gamma \delta)$ heterodimer [1]. These $\gamma \delta \mathrm{T}$ cells are mostly dual-negative CD4-/CD8- [2], express some natural killer antigens, and have a cytotoxic phenotype [3]. $\gamma \delta$ $\mathrm{T}$ cell lymphomas are rare, and the most common subtypes include primary cutaneous forms and the hepatosplenic $\gamma \delta \mathrm{T}$ cell lymphomas $[4,5]$. Both of these subtypes usually have a cytotoxic $\mathrm{T}$ cell phenotype, are often dual CD4-/CD8- or $\mathrm{CD} 8+$, and may have secondary involvement of the peripheral blood and bone marrow, but very rarely involve the lymph nodes [6], with a homing pattern that mimics our current

Kristin H. Karner

Kristin.karner@aruplab.com

1 Department of Pathology, School of Medicine, University of Utah, Salt Lake City, UT, USA

2 Department of Pathology and Laboratory Medicine, Henry Ford Health System, Detroit, MI, USA understanding of normal $\gamma \delta$ T cells, involving sinusoidal areas of the spleen, gastrointestinal mucosal surfaces, and skin [7] and also the respiratory tract [8].

We report an unusual case of $\gamma \delta$ T cell lymphoma with a rare phenotype (CD4 positive, lacking cytotoxic markers) and rare clinical presentation with multiple subcutaneous nodules and extensive lymph node involvement. The CD4+ immunophenotype with this pattern of involvement is extremely rare in the literature and has only been reported in three other patients to the best of our knowledge $[9,10]$. This may represent an unusual and yet unrecognized type of $\gamma \delta \mathrm{T}$ cell lymphoma. In a large series of gamma delta $T$ cell lymphomas by Garcia-Herrera et al. [6], none of the cases were CD4 positive. Unique to our case is the cutaneous aspect of involvement and that our patient had a renal transplant 1 year prior to this presentation and was on immunosuppressive medication.

\section{Clinical history}

A 66-year-old Caucasian male former smoker (40-pack year history) presented with a 6-month history of pruritic skin rash and, for the past 1-2 months, had worsening and more rapidly enlarging non-ulcerative subcutaneous nodules with concurrent 
weakness, B symptoms, weight loss, and inguinal lymphadenopathy. A mass on the nose was also rapidly enlarging. Previous biopsies of the skin at outside institutions were diagnosed as granuloma annulare and chronic spongiotic dermatitis.

He was admitted to the hospital for hypercalcemia and acute kidney injury. One year earlier, he had a renal transplant from an unrelated donor for end-stage renal disease related to diabetic nephropathy and was subsequently placed on immunosuppressive therapy including tacrolimus and mycophenolate mofetil. He has also had persistent BK polyoma viremia $\left(>10^{6} \mathrm{IU} / \mathrm{mL}\right)$.

A CT scan showed significant generalized lymphadenopathy involving the supraclavicular, axillary, chest, abdominal, and pelvic lymph nodes up to $6 \mathrm{~cm}$ in the greatest dimension.

An axillary lymph node biopsy was performed and was diagnosed as a $\mathrm{T}$ cell lymphoma of gamma delta phenotype. Subsequently, a punch biopsy of the right back skin lesion was performed, which showed similar results. A staging bone marrow biopsy showed low-level involvement by the T cell lymphoma.

The patient was started on the EPOCH regimen (prednisone, etoposide, vincristine, cyclophosphamide, and doxorubicin) and, 5 days later, developed a neutropenic fever and started receiving filgrastim. Immunosuppression was reduced, including cessation of tacrolimus, continuing mycophenolate mofetil and adding everolimus. The patient completed 6 cycles of EPOCH, after which PET CT showed a partial response in the lymph nodes. Skin lesions had resolved.

Nine months after initial diagnosis, a PET scan demonstrated significant progression of disease with new cutaneous lesions, liver lesions, splenic lesions, and inguinal and iliac lymphadenopathy. He is currently being treated with supportive care while a salvage chemotherapy regimen is being considered if his performance status improves.

\section{Materials and methods}

\section{Morphologic studies and immunohistochemistry}

Specimens from the lymph node and skin punch biopsy were fixed in formalin and processed according to standard protocols. Paraffin sections were stained with hematoxylin and eosin. Bone marrow aspirate smears were stained with Wright-Giemsa. The bone marrow clot and core biopsy specimens were fixed in formalin, sectioned after decalcification of the core biopsy, and stained with hematoxylin and eosin by standard protocol.

An immunohistochemical panel was performed on the lymph node and partial panel on the skin biopsy on paraffin sections, using the peroxidase-antiperoxidase and avidinbiotin complex method with appropriate positive and negative controls. The following antibodies were performed: $\mathrm{CD} 2$, CD3, CD4, CD5, MIB1, CD7, CD8, CD10, CD20, CD30, CD34, CD56, CD68, AE1/AE3, ALK1, BCL-1, BCL-2,
BCL-6, PAX5, PD-1, TdT, TCL1, CXCL13, beta F1, and TCR delta (clone H-41). In addition, an EBV stain for early RNA transcripts EBER-1 and EBER-2 by chromogenic in situ hybridization was also performed.

\section{Flow cytometry}

Six-color flow cytometry was performed on the lymph node biopsy on a FACSCanto cytometer using FACSDiva software (Becton-Dickinson, San Jose, CA). Primary lymphocyte gating utilized CD45 and side light scatter (SSc) of the CD45+ bright/SSc low population. The following antibody panels were used: $\mathrm{CD} 2, \mathrm{CD} 3, \mathrm{CD} 4, \mathrm{CD} 5, \mathrm{CD} 7, \mathrm{CD} 8, \mathrm{CD} 10$, CD11c, CD16, CD19, CD20, CD23, CD25, CD45, CD56, CD57, TCR alpha beta, and TCR gamma delta (BectonDickinson, San Jose, CA). Antigen intensity, as compared to the intensity of the corresponding normal cell type, was interpreted as negative, dim, normal, or bright.

\section{T cell receptor gene rearrangements by polymerase chain reaction}

DNA was extracted from unstained sections of formalin-fixed paraffin-embedded tissue from the skin biopsy and lymph node and from unstained aspirate smears of the bone marrow biopsy, according to standard protocol. Genomic DNA was amplified by polymerase chain reaction, targeting multiple $\mathrm{V}$ and $\mathrm{J}$ exon regions in both the $\mathrm{T}$ cell receptor beta and gamma chain loci. PCR products were then analyzed by differential fluorescence detection using capillary electrophoresis. All reactions were run in duplicate.

\section{Results}

Flow cytometry of the lymph node biopsy showed a phenotype positive for CD2, CD3, CD4, CD5, CD45, and TCR gamma delta. CD7 was abnormally dim to negative (Fig. 1). The neoplastic cells were negative for CD8, CD10, CD11c, CD16, CD19, CD20, CD23, CD56, and TCR alpha beta. CD57 expression could not be determined. Additional phenotyping by immunohistochemistry showed the following: negative for CXCL13, CD30, PD-1, TdT, TCL1, and TCR beta F1. TCR delta was strongly and diffusely positive. EBER in situ hybridization was negative. Molecular gene rearrangement studies for both TCR beta and TCR gamma were positive. The morphology of the axillary lymph node showed diffuse effacement of the architecture by intermediate-sized lymphocytes with a moderate amount of clear cytoplasm and prominent high endothelial venules (Figs. 2 and 3). A diagnosis of CD4+ $4 \delta \mathrm{T}$ cell lymphoma was rendered.

The punch biopsy of the right back skin lesion showed the same $\mathrm{T}$ cell clone and an immunophenotype essentially 
Fig. 1 Flow cytometric analysis of the lymph node from our patient shows an

immunophenotype expressing CD3, CD4, and gamma delta with partial loss of CD7, negative for CD8 and alpha beta
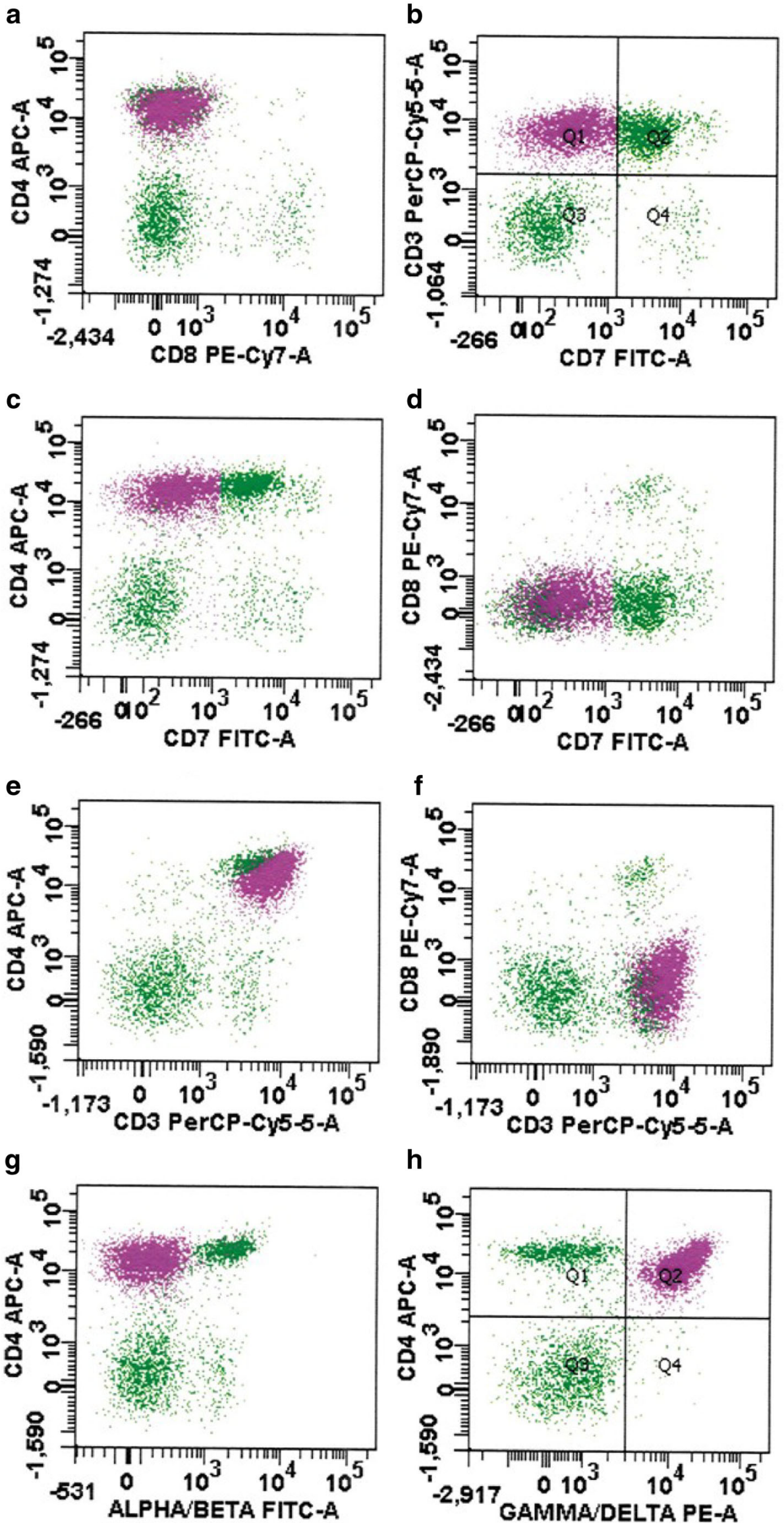

h

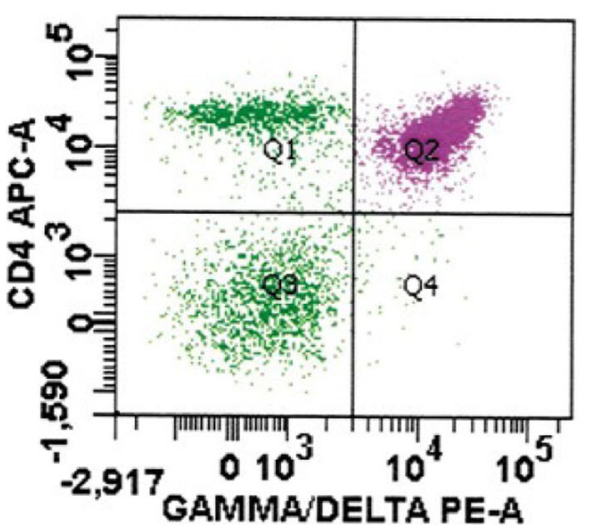




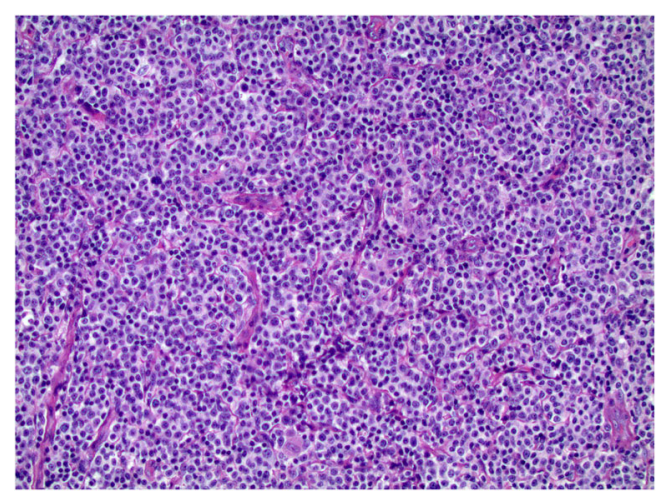

Fig. $2 \mathrm{H} \& \mathrm{E}(\times 200$ magnification $)$ section of the lymph node highlights the effacement of normal architecture by a proliferation of atypical medium-sized lymphocytes in a vaguely nodular pattern. High endothelial venules are prominent

similar to the lymph node, with the only major difference being partial loss of CD2. The lymphocytes, however, showed greater atypia and pleomorphism. They were confined to the dermis, extending to the lower border of the biopsy, without any apparent epidermal involvement (Fig. 4).

The bone marrow biopsy showed a low level of positivity. While obvious lymphoid aggregates were not observed on the H\&E section, a few small aggregates of atypical T lymphocytes could be seen using immunohistochemical staining methods (CD3, CD4). Of note, this was not reminiscent of the predominantly intrasinusoidal pattern typically seen with hepatosplenic gamma delta T cell lymphomas. These T cells were confirmed to represent involvement by the gamma delta $\mathrm{T}$ cell lymphoma as they showed the same pattern of expression by flow cytometry, including co-expression of CD4 and gamma delta, and showed the same clone size by PCR analysis of the T cell receptor.

\section{Discussion}

CD4+ expression in $\gamma \delta$ T cell lymphomas is exceedingly rare, and aside from our case, only four verifiable cases have been

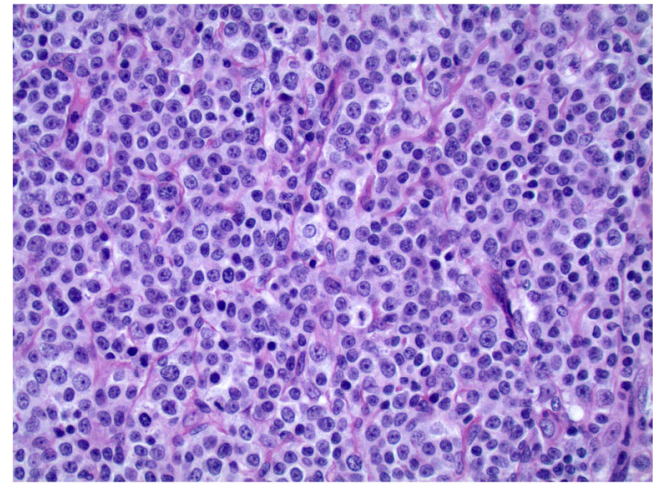

Fig. 3 H\&E staining of the same lymph node at higher power $(\times 400$ magnification) shows atypical medium-sized cells with abundant clear cytoplasm

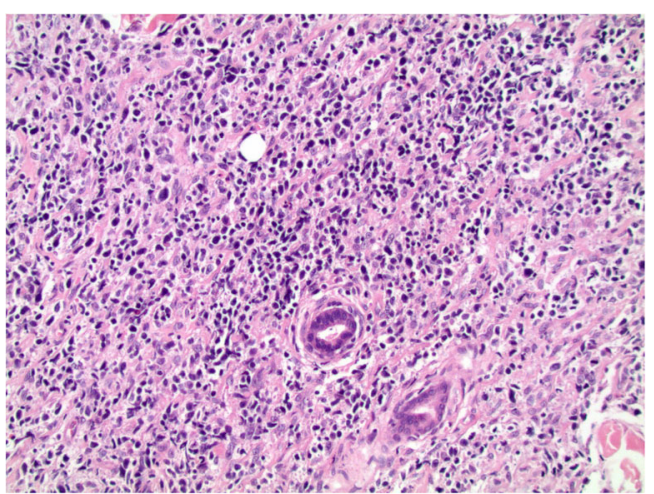

Fig. $4 \mathrm{H} \& \mathrm{E}$ staining of the skin biopsy $(\times 40$ magnification) shows dense dermal and subcutaneous infiltration by small- to medium-sized atypical lymphocytes

reported in the literature [9-11] with another case that showed partial weak CD4 expression [12]. Another three cases are of questionable diagnosis due to beta F1 expression [13]. While a peripheral $\mathrm{T}$ cell lymphoma, not otherwise specified, was a primary consideration in the differential diagnosis in our case, the expression of TCR delta by immunohistochemical staining methods with the absence of TCR beta F1 confirmed the $\gamma \delta$ phenotype.

$\gamma \delta \mathrm{T}$ cell lymphoma, particularly the hepatosplenic variety, has been associated with and is well documented in immunosuppressed individuals [14]. In contrast, our case with the CD4+ phenotype and nodal-based presentation is distinctly different from the hepatosplenic variety of gamma delta $\mathrm{T}$ cell lymphoma and has not yet been reported in the setting of immunosuppression. One case of nodal-based $\gamma \delta$ T cell lymphoma was also in a renal transplant patient but did not share the CD4+ phenotype and had a sinusoidal rather than PTCLlike pattern [15]. For comparison of the 42 well-documented cases of hepatosplenic $\gamma \delta$ T cell lymphoma (HSTL) cited in the literature at the time of publication, Khan et al. [3] reported that eight cases were in immunocompromised individuals. Both HSTLs and nodal-based $\gamma \delta$ T cell lymphomas have rare cases reported to be EBV positive [3, 10, 16].

While hepatosplenic $\gamma \delta \mathrm{T}$ cell lymphomas have been reported post-renal transplant, the cutaneous form of gamma delta T-NHL is extremely rare in this setting. The only other reported case to the best of our knowledge is by Prillinger et al. [17] who describe a patient with a long history of mycosis fungoides (MF) that developed cutaneous gamma delta T cell lymphoma (TCL) presumably as a progression from his underlying MF following renal transplant.

Prognosis is typically dismal in most cases of $\gamma \delta \mathrm{T}$ cell lymphoma, and CD4+ cases do not appear to be significantly different. Of the four cases with CD4 expression, there was a mean overall survival of 8.15 months. Of the 13 cases with lymph node involvement, regardless of CD4 status, the mean overall survival was similar at 9.12 months. These are compared to reports from the literature of an overall survival for 
hepatosplenic gamma delta $\mathrm{T}$ cell lymphoma of less than 2 years [18] and about 15 months for primary cutaneous gamma delta T cell lymphoma $[19,20]$. However, of the few nodal-based cases reported in the literature, the case described by Kagami et al. [16] did go into complete remission after initial therapy; however, the patient relapsed 2 years later with a higher-grade morphology and clonal EBV positivity in the neoplastic cells and died 40 days after relapse in the lymph nodes, peripheral blood, and bone marrow.

Under certain conditions of prolonged immunosuppression and chronic antigen exposure, there may be a proliferation of initially benign, reactive $\gamma \delta \mathrm{T}$ lymphocytes that play a significant role in the immune response but, at some point, can result in the development of $\gamma \delta$ T cell lymphomas [21], drawing some comparison to the chronic inflammation and chronic antigenic stimulation associated with marginal zone lymphomas of B cell lineage. Expansion of reactive $\gamma \delta$ T cell subsets has been reported with such diseases as celiac sprue [22] and sarcoidosis [23]. Renal transplant patients with BK virus infection, such as our patient, are believed to have increased stimulation of $\gamma \delta \mathrm{T}$ cells, based on observations from in vitro studies [24], and it is postulated that chronic antigenic stimulation of the $\gamma \delta$ T cell population may have played a role in lymphomagenesis.

$\gamma \delta \mathrm{T}$ cell lymphomas are not a uniform group but have a variety of presentations, outcomes, genetic profiles, and other indications that suggest that this is actually a heterogeneous group of diseases [6]. For example, a high proportion of monomorphic epitheliotropic intestinal $\mathrm{T}$ cell lymphomas (formerly known as type II enteropathy-associated T cell lymphoma, but now known to be entirely distinct from type I EATL) [5] are also derived from $\gamma \delta \mathrm{T}$ cells. There are also cases of mycosis fungoides that may show a $\gamma \delta$ phenotype. In addition, recent evidence indicates better prognosis for primary cutaneous gamma delta $T$ cell lymphoma with predominantly epidermotropic involvement as compared to the typical dermal and subcutaneous involvement [25]. These examples illustrate how T cell lymphomas with a $\gamma \delta$ phenotype should not be thought of as a single entity with a standard behavior.

A few cases are accumulating in the literature $[9,10,15,16$, 26], and now, our case describes $\gamma \delta \mathrm{T}$ cell lymphomas with non-cytotoxic immunophenotypic profiles and nodal-based disease. Table 1 shows the characteristics of the patients in this group and the immunophenotype of each case. This begs the question of whether such cases (immunocompetent or not) that lack cytotoxic markers which occasionally express CD5 and sometimes CD4 (in contrast to the majority of gamma delta TCL) are biologically different, albeit rare, and deserve to be classified as their own separate entity or perhaps as a subset of peripheral T cell lymphoma, not otherwise specified.

Charton-Bain et al. [15] report two patterns of lymph node involvement, one mimicking a typical alpha beta type of $\mathrm{T}$ cell lymphoma with total lymph node effacement (as seen in our case) and one with an intrasinusoidal pattern of involvement. It is interesting to note that all of the CD4+ cases show the pattern of total effacement rather than sinusoidal involvement, while it is reported that hepatosplenic and bone marrow involvement are associated more commonly with the sinusoidal pattern of lymph node involvement. Might these divergent architectural

Table 1 Patient characteristics and immunophenotype of CD4+ or nodal-based gamma delta T cell lymphoma

\begin{tabular}{|c|c|c|c|c|c|c|c|c|c|c|c|c|c|c|c|c|c|c|}
\hline Reference & Year & Case & Age & Sex & $\mathrm{LN}$ & $\mathrm{gd}$ & $a b$ & $\mathrm{CD} 3$ & $\mathrm{CD} 4$ & CD8 & $\mathrm{CD} 2$ & $\mathrm{CD} 5$ & CD7 & EBV & CD57 & CD56 & Gran B & $\begin{array}{l}\text { TIA- } \\
1\end{array}$ \\
\hline deSouza et al. [11] & 2007 & 1 & 74 & M & & + & - & + & + & - & + & + & + & - & ND & ND & ND & ND \\
\hline Ichinohasama et al. [9] & 1996 & 2 & 72 & M & + & + & - & + & + & - & + & + & - & - & - & - & ND & ND \\
\hline \multirow[t]{3}{*}{ Saito et al. [10] } & \multirow[t]{3}{*}{2002} & 3 & 66 & M & + & + & - & + & + & - & ND & - & ND & - & ND & - & - & - \\
\hline & & 4 & 79 & M & + & + & - & + & + & - & ND & + & ND & - & ND & ND & - & + \\
\hline & & 5 & 64 & $\mathrm{M}$ & + & + & - & + & - & - & ND & - & ND & + & ND & ND & + & - \\
\hline Kagami et al. [16] & 1997 & 6 & 70 & $\mathrm{~F}$ & + & + & - & + & - & + & + & - & + & + & - & - & ND & ND \\
\hline \multirow[t]{2}{*}{ Charton-Bain et al. [15] } & \multirow[t]{2}{*}{2000} & 7 & 44 & $\mathrm{M}$ & + & + & - & + & - & - & + & - & - & Rare & - & - & + & + \\
\hline & & 8 & 24 & $\mathrm{M}$ & + & + & - & + & - & - & + & - & - & - & ND & ND & - & + \\
\hline Lima et al. [26] & 2003 & 9 & 45 & $\mathrm{~F}$ & + & + & ND & + & - & - & + & ++ & - & - & - & - & - & ND \\
\hline \multirow[t]{5}{*}{ Garcia-Herrera et al. [6] } & \multirow[t]{5}{*}{2011} & 10 & 49 & $\mathrm{~F}$ & + & + & - & + & - & - & ND & - & ND & + & ND & + & + & + \\
\hline & & 11 & 24 & M & + & + & - & + & - & + & ND & - & ND & + & ND & - & + & ND \\
\hline & & 12 & 16 & $\mathrm{~F}$ & + & + & - & + & - & - & ND & - & + & - & ND & - & + & + \\
\hline & & 13 & 57 & $\mathrm{~F}$ & + & + & - & + & - & - & ND & - & - & + & ND & - & + & + \\
\hline & & 14 & 29 & M & + & + & - & + & - & - & ND & + & + & - & - & - & + & ND \\
\hline Anil et al. [12] & 2016 & 15 & 57 & $\mathrm{~F}$ & & + & $*$ & + & $\mathrm{P}$ & $*$ & ND & ND & - & - & ND & ND & + & ND \\
\hline
\end{tabular}

CD4+ cases are presented in rows 2-5, columns 3-19

$L N$ lymph node involvement, $N D$ not done, $P$ partial

* Positive, but unclear in which population 
patterns and immunophenotypes (CD4+ vs. CD4 negative) be a clue as to distinctly different $\gamma \delta$ subtypes with unique behaviors and homing patterns? Should they be treated as separate entities? To answer this question, it may be helpful to look at the different roles of CD4-negative and CD4-positive $\gamma \delta$ T cells in the normally functioning immune system.

$\mathrm{xCD} 4+\gamma \delta \mathrm{T}$ cells have been identified as rare, naturally occurring cells in the normal human immune system. It is estimated that $1-4 \%$ of $\gamma \delta \mathrm{T}$ cells can express CD4 [27]. This has been confirmed by isolation and cloning of these cells from the human liver [28] and peripheral blood [29, 30]. They are thought to begin as immature precursors, identified in the bone marrow, that express immature markers including CD34 and TdT [31]. Prompted by mild inflammatory states, they are thought to undergo a differentiation process not unlike what occurs in the thymic tissue, eventually losing their immature markers, downregulating the delta 1 receptor and gaining alpha beta receptors, with differentiation to CD4+ or $\mathrm{CD} 8+$ alpha beta $\mathrm{T}$ cells. If this $\mathrm{CD} 4+\gamma \delta$ phenotype seen in our patient does, in fact, have a naturally occurring cell of origin, it may only exist for a brief period of time, as the immature $\gamma \delta \mathrm{T}$ cells progress through an intermediate stage on their way to becoming mature alpha beta-expressing $\mathrm{T}$ cells. As this pool of cells already makes up a very minor fraction of the total $\mathrm{T}$ cell population, this is one possible explanation as to why this phenotype is so exceedingly rare. This explanation does not, however, adequately explain the tendency of this phenotype to home to the lymph nodes. Few studies have examined the potential functionality of normal $\mathrm{CD} 4+\gamma \delta \mathrm{T}$ cells, but some work has been done, indicating a different role than CD4-negative $\gamma \delta \mathrm{T}$ cells. CD4+ subsets appear to have less potent cytotoxic activity compared to the other $\gamma \delta$ subsets, but they do release high levels of cytokines upon antigen stimulation and, also in contrast to the CD4negative subset, can assist in immunoglobulin production by B cells (helper phenotype) [27]. This is interesting because this helper function does not directly involve the T cell receptor but there is a correlation between CD4 expression and helper function, regardless of alpha beta or $\gamma \delta$ TCR subtype.

Admittedly, the number of cases reported in the literature is too few to draw many conclusions about this entity with statistical certainty. Naturally occurring CD4 $+\gamma \delta$ T cell subsets are currently not well understood and appear to be a very small population, making them difficult to study. It is interesting to consider a cell of origin theory in the case that we present, rather than an aberrant immunophenotype. The paucity of these cells naturally occurring in healthy individuals may help to explain why this entity is so exceedingly rare. Despite all of these differences, survival outcomes do appear to be similar to other types of $\gamma \delta \mathrm{T}$ cell lymphoma.

Conflict of interest The authors declare that they have no conflict of interest.

\section{References}

1. Esin S, Shigematsuu M, Nagaiu S et al (1996) Different percentages of peripheral blood gamma delta $+\mathrm{T}$ cells in healthy individuals from different areas of the world. Scand J Immunol 43:593-596

2. Kabelitz D (1992) Function and specificity of human gamma/delta T-positive cells. Crit Rev Immunol 11:281-303

3. Khan WA, Yu L, Eisenbrey AB, Crisan D, Saadi AA, Davis BH, Hankin RC, Mattson JC (2001) Hepatosplenic gamma/delta T-cell lymphoma in immunocompromised patients. Am J Clin Pathol 116:41-50

4. Swerdlow SH, Campo E, Harris NL et al (eds) (2008) WHO classification of tumours of haematopoietic and lymphoid tissues. Lyon, IARC

5. Swerdlow SH, Campo E, Harris NL, Jaffe ES, Pileri SA, Stein H, Thiele J (eds) (2017) WHO classification of tumours of hematopoietic and lymphoid tissues (revised), 4th edn. Lyon, IARC

6. Garcia-Herrera A, Song JY, Chuang SS, Villamor N, Colomo L, Pittaluga S, Alvaro T, Rozman M, de Anda Gonzalez J, Arrunategui AM, Fernandez E, Gonzalvo E, Estrach T, Colomer D, Raffeld M, Gaulard P, Campo E, Jaffe ES, Martinez A (2011) Nonhepatosplenic gamma delta T-cell lymphomas represent a spectrum of aggressive cytotoxic T-cell lymphomas with a mainly extranodal presentation. Am J Surg Pathol 35:1214-1225

7. Bucy PR, Chen CH, Cooper MD (1989) Tissue localization and CD8 accessory molecule expression of $\mathrm{T}$ gamma/delta cell in humans. J Immunol 142:3045-3049

8. Chan JK, Chan AC, Cheuk W et al (2011) Type II enteropathyassociated T-cell lymphoma: a distinct aggressive lymphoma with frequent $\gamma \delta$ T-cell receptor expression. Am J Surg Pathol 35:1557-1569

9. Ichinohasama R, Miura I, Takahashi T, Yaginuma Y, Myers J, Decoteau JF, Yee C, Kadin ME, Mori S, Sawai T (1996) Peripheral CD4+ CD8- $\gamma \delta \mathrm{T}$ cell lymphoma: a case report with multiparameter analyses. Hum Pathol 27:1370-1377

10. Saito T, Matsuno Y, Tanosaki R et al (2002) $\gamma \delta$ T-cell neoplasms: a clinicopathological study of 11 cases. Ann Oncol 13:1792-1798

11. deSouza MHO, Hassan R, Stefanoff CG et al (2007) CD4+ gamma/ delta T-cell leukemia/lymphoma: clinical, immunophenotypic and molecular aspects in an unusual case. Haematologica 88:e120-e122

12. Anil R, Grover S, Hiremath A (2016) A rare case of cutaneous gamma delta T-cell lymphoma with complete body involvement. J Med Cases 7:364-367

13. Vin H, Talpur R, Tetzlaff MT, Duvic M (2014) T-cell receptorgamma in gamma-delta phenotype cutaneous T-cell lymphoma can be accompanied by atypical expression of CD30, CD4, or TCRbetaF1 and an indolent clinical course. Clin Lymphoma Myeloma Leuk 14:e195-e200

14. Yabe M, Medeiros LJ, Daneshbod Y, Davanlou M, Bueso-Ramos CE, Moran EJ, Young KH, Miranda RN (2017) Hepatosplenic Tcell lymphoma arising in patients with immunodysregulatory disorders: a study of 7 patients who did not receive tumor necrosis factor-alpha inhibitor therapy and literature review. Ann Diagn Pathol 26:16-22

15. Charton-Bain MC, Brouseet P, Bouabdallah R et al (2000) Variation in the histological pattern of nodal involvement by gamma/delta Tcell lymphoma. Histopathology 36:233-239

16. Kagami Y, Nakamura S, Ritsurou S et al (1997) A nodal gamma/ delta T-cell lymphoma with an association of Epstein-Barr virus. Am J Surg Path 21:729-736

17. Prillinger KE, Trautinger F, Kitzwogerer M et al (2017) Two faces of gamma-delta mycosis fungoides: before and after renal transplantation. BMJ Case Rep. https://doi.org/10.1136/bcr-2016-216990

18. Belhadj K, Reyes F, Farcet JP et al (2003) Hepatosplenic gamma delta T-cell lymphoma is a rare clinicopathologic entity with poor outcome: report on a series of 21 patients. Blood 102:4261-4269 
19. Toro JR, Liewehr DJ, Pabby N et al (2003) Gamma-delta T-cell phenotype is associated with significantly decreased survival in cutaneous T-cell lymphoma. Blood 101:3407-3412

20. Willemze R, Jansen PM, Cerroni L et al (2007) Subcutaneous panniculitis-like T-cell lymphoma: definition, classification and prognostic factors. Blood 111:838-845

21. Foppoli M, Ferreri AJM (2014) Gamma-delta T-cell lymphomas. Eur J Haematol 94:206-218

22. Kutlu T, Rambaud C, Le Deist F et al (1992) Numbers of T-cell receptor (TCR) ab+ but not of TCR gd+ intraepithelial lymphocytes correlate with the grade of villous atrophy in coeliac patients on a long term diet. Gut 34:208-219

23. Shigehara K, Shijubo N, Nakanishi F, Hirasawa M, Inuzuka M, Ohmichi M, Hiraga Y, Abe S (1995) Circulating gd-T-cell receptor-positive lymphocytes in sarcoidosis. Respiration 62:84-88

24. Comoli P, Basso S, Azzi A et al (2003) Dendritic cells pulsed with polyomavirus $\mathrm{BK}$ antigen induce ex vivo polymoma BK virusspecific cytotoxic T-cell lines in seropositive healthy individuals and renal transplant recipients. J Am Soc Nephrol 14:3197-3204

25. Merrill ED, Agbay R, Miranda RN, Aung PP, Tetzlaff MT, Young KH, Curry JL, Nagarajan P, Ivan D, Prieto VG, Medeiros LJ, Duvic M, Torres-Cabala CA (2017) Primary cutaneous T-cell lymphomas showing gamma-delta phenotype and predominantly epidermotropic pattern are clinicopathologically distinct from classic primary cutaneous gamma delta T-cell lymphomas. Am J Surg Pathol 41:204-215

26. Lima M, Canelhas A, Santos C, Teixeira MA, Coutinho J, Alves R, Queirós ML, Fonseca S, Santos AH, Gonçalves V, Massa A, Justiça B (2003) Non-cytotoxic gamma-delta peripheral T-cell lymphoma affecting the mandibular and parotidal lymph nodes and the skin. Leuk Lymph 44:525-529

27. Spits H, Paliard X, Vendekerckhove Y, van Vlasselaer P, De Vries JE (1991) Functional and phenotypic differences between CD4+ and CD4- $\mathrm{T}$ cell receptor- $\gamma \delta$ clones from peripheral blood. J Immunol 147:1180-1188

28. Aparicio P, Alonso JM, Toribio ML et al (1989) Isolation and characterization of gamma delta CD4+ T cell clones derived from human fetal liver cells. J Exp Med 170:1009-1014

29. Vietor H, Koning F (1990) Gamma delta T-cell receptor repertoire in human peripheral blood and thymus. Immunogenetics 31:340-346

30. Paliard X, Yssel H, Blanchard D et al (1989) Antigen specific and MHC nonrestricted cytotoxicity of T cell receptor alpha beta+ and gamma delta+ human T cell clones isolated in IL-4. J Immunol 143: $452-457$

31. Ziegler H, Welker C, Sterk M et al (2014) Human peripheral CD4+ Vdelta1 $+\gamma \delta \mathrm{T}$ cells can develop into alpha beta T cells. Front Immuno 5:645 